\title{
Hacia una mejor comprensión del papel de la naturaleza en los debates bioéticos
}

\author{
LYDIA FEITO GRANDE \\ Universidad Complutense de Madrid (España) \\ lydia.feito@med.ucm.es
}

\begin{abstract}
Resumen
En los debates bioéticos actuales es frecuente encontrar apelaciones a la naturaleza como modo de justificar determinadas opciones morales. Así, la llamada a una presunta «naturaleza» del ser humano, o la aparentemente incuestionable «ley natural» se convierten en baluartes de una ética poco dispuesta a renunciar a ese sustrato inamovible y fiable. Sin embargo, este planteamiento exige ser revisado. Más que de naturaleza humana es preciso hablar de capacidades o elementos que posibilitan las opciones humanas.

Palabras clave: bioética, naturaleza humana, ley natural, orden, falacia naturalista, bioconservadores, transhumanistas.
\end{abstract}

\section{To a better understanding of the role of nature in bioethical debates}

\begin{abstract}
In the present bioethical debates is usual finding appeals to nature as a way to justify certain moral options. Therefore, the invocation of a supposed "nature" of human beings, or the seemingly unquestionable "natural law" turn into bastions of an ethics not willing to abandon a fixed and reliable substratum. Nonetheless this approach must to be revised. Instead of buman nature is required to deal with capacities of elements which make possible the buman options.
\end{abstract}

Key words: bioethics, buman nature, natural law, order, naturalistic fallacy, bioconservaties, transhumanists.

Doctora en Filosofía y Letras por la Universidad Pontificia Comillas de Madrid. Magíster en Bioética y también en Neuropsicología Cognitiva y Neurología Conductual por la Universidad Complutense de Madrid. Actualmente es profesora de Bioética por la misma universidad, donde es Directora del Seminario de Investigación en Bioética de la Facultad de Medicina. Forma parte de la Asociación de Bioética Fundamental y Clínica (Madrid) y del Grupo de Ética y Buenas Prácticas de la Sociedad Española de Fertilidad, entre otras. Entre sus abundantes publicaciones destacan los libros El sueño de lo posible. Bioética y terapia génica (1999), Ética profesional de la enfermería (2000) y Ética y enfermería (2009). También es editora y autora de los libros Estudios de bioética (1997) y Bioética: la cuestión de la dignidad (2004). 


\section{El orden de la naturaleza y el ser humano}

En 1689 J. Locke escribió su Carta sobre la tolerancia, con ella no sólo pretendía llamar la atención sobre el hecho de que no existe una única verdad religiosa, sino, sobre todo, incidir en la necesidad del respeto mutuo - un elemento absolutamente imprescindible para la deliberación moral- Tal cosa tiene importancia por varias razones, que atañen a la cuestión que aquí nos ocupa.

En primer lugar, plantea la necesidad de la articulación entre posturas divergentes, en lo que a materia de creencias se refiere. Buena parte de los problemas bioéticos actuales, además de cuestiones a analizar y conflictos que resolver, son desafíos que nos obligan a la determinación de nuestras propias convicciones. De ahí la imprescindible introducción de un mecanismo de corrección de los posibles dogmatismos de la autoconvicción en la propia verdad. Ese mecanismo correctivo tiene dos dimensiones: la de la escucha plural, respetuosa, comprehensiva, de las opiniones y convicciones de otros, por un lado, y la más dedicada a la toma de decisiones, donde es preciso articular convicciones con responsabilidad.

Por otro lado, la enseñanza de Locke acerca de la necesaria división entre las leyes de los hombres y los mandatos de las creencias, insiste en algo que ya los filósofos de su época estaban planteando: es lo que Descartes nos muestra con su llamada de atención sobre el engaño de los sentidos, de lo que los racionalistas acusan a los empiristas ingenuos, lo que conmueve los cimientos del pensamiento occidental tras siglos de convicción en un código único epistemológico y moral. La naturaleza no es ya pauta de moralidad. No puede serlo. La confianza ciega en un presunto orden natural que ha sido instituido, ya sea por Dios o por las mismas fuerzas del universo, está basada en tres afirmaciones difícilmente sostenibles: (1) que existe tal orden en la naturaleza, (2) que ese orden anterior y superior al ser humano, es bueno en sí mismo y no admite rectificación o enmienda, y (3) que el ser humano tiene la capacidad de conocer tal orden y debe asumirlo. Ninguna de estas afirmaciones es evidente en sí misma, antes bien, las tres están profundamente cuestionadas y son insostenibles desde los esquemas cognitivos elaborados a partir del siglo XVII.

Que haya orden en la naturaleza es algo cuando menos sorprendente. A pesar de que pueda ser posible afirmar una cierta teleonomía en la naturaleza, es claro que ésta dista de establecer una pauta organizativa unívoca y perfecta. Antes bien, parece que el método de ensayo y error es el más frecuente, y que el azar, si bien puede no ser el único motor de la evolución o los cambios de la naturaleza, desde 
luego es uno de los más importantes. Todo ello contribuye a la afirmación de que la naturaleza, por más que queramos proyectar en ella un presunto orden, incluso buscando leyes al caos, dista mucho de ser una maquinaria compleja pero predecible y determinada, como querían los pensadores mecanicistas del Renacimiento y la Modernidad.

Por otro lado, la naturaleza, incluso en su presunto orden, muestra datos y fenómenos que difícilmente pueden ser catalogados como buenos o deseables. El equilibrio inestable en que se dan buena parte de las acciones naturales, no deja de ser algo que se describe y explica, pero que no puede ser catalogado como «bueno» o «malo» en sí mismo. La asignación de valor es un producto humano, y no viene predeterminado naturalmente. De ahí que Locke pueda decir que no todos los seres humanos observan igualmente las mismas cosas ni, por supuesto, le otorgan la misma importancia o valor. Es la denuncia que hace Hume, al percibir un planteamiento injustificado e irracional en la derivación de lo que la realidad deba ser a partir de lo que de hecho sea. La naturaleza presenta un cierto modo de ser que, no por darse así, ha de ser necesariamente deseable o defendible. De hecho, el ser humano se empeña en imponerle a la naturaleza una «sobrenaturaleza» una suerte de «segunda naturaleza», como ya dijera Ortega y Gasset, que es su modo propio de estar en el mundo, una modificación imprescindible que es «perfectamente natural» en tanto que connatural al ser de los humanos, por su condición de radicales «animales técnicos», pero que, desde luego, dista de estar predeterminada o tener una única vía de intervención. De ahí que el ser humano esté «condenado a ser libre», abocado a la justificación de sus actos, necesitado de la elección y de la asignación de valores que le permitan tomar decisiones, en última instancia, el ser humano está obligado a la deliberación racional sobre los fines de sus actos, porque sólo así será capaz de dotar de sentido su existencia y podrá encontrar el «orden» de su mundo.

Por eso es difícil afirmar que el presunto orden de la naturaleza, caso de que exista, pueda ser considerado como bueno de modo acrítico. La acción de los virus, por ejemplo, es perfectamente natural, pero no suele ser catalogada como buena, si afecta al ser humano provocándole una enfermedad. $Y$ el ser humano se siente perfectamente legitimado moralmente para luchar contra la naturaleza, destruyendo al virus, modificándolo, adaptándolo a sus intereses, salvando su vida, que considera más valiosa. Y para ello pone en marcha un mecanismo de justificación de sus actos. Porque tampoco es evidente que ésta acción sea buena en sí misma: lo será sólo en cuanto seamos capaces de dar razón de ella. 
Por tanto, la naturaleza no es pauta de moralidad. Y, aún más, admitir tal cosa supondría que el ser humano es un ser determinado, un ser que carece de libertad y que sólo puede someterse a los mandatos de una naturaleza que establece sus propias pautas. En este sentido, su comportamiento no sería diferente del de las olas del mar, y habría que afirmar que la inteligencia es, entonces, un destello inútil (como lo llama F. Nietzsche) un fuego fatuo que sólo nos permite una cierta soberbia, pero que es sólo la patética expresión de una ilusión. Si el ser humano no es más que una máquina sometida a los dictados de su «ser natural», qué gasto más inútil el de estar dotado de inteligencia. Sin embargo, ¿cómo explicar, entonces, acciones tan «poco naturales» y poco prácticas, como la creación artística?

Sin embargo, conviene no exaltar la inteligencia hasta el punto de volver a incurrir en el mismo peligro que se trata de evitar: un exceso de confianza en la razón puede derivar en la afirmación, también ingenua, de que el ser humano tiene la capacidad de conocer ese presunto orden inscrito en la naturaleza. Tal cosa ya fue destacada por Descartes y otros pensadores al notar la deficiencia de nuestro conocimiento entendido como acceso directo a la realidad y conocimiento verdadero de la misma. Nuestro conocimiento está teñido de categorías, filtrado por capacidades y presupuestos teóricos - como ya destacaran autores tan diferentes como I. Kant o N. R. Hanson- sin los que no podemos entender el mundo. Y es también limitado, no lo puede todo. De ahí que haya que afirmar sus carencias y definir sus posibilidades. En el hipotético caso de que existiera un orden en la naturaleza, ¿cómo podríamos conocerlo?, ¿cómo podríamos saber que no se trata de una proyección de nuestro entendimiento, de una figuración derivada de nuestras expectativas, nuestros conocimientos previos, nuestros objetivos, nuestras capacidades?, ¿cómo podríamos estar seguros de que no es un engaño que parece verdadero sin serlo? Parece más convincente la posición que asume que el orden es algo construido por nuestra razón. El apoyo en la realidad es necesario, pero no es suficiente, ni absoluto. De ahí la pluralidad de posiciones, de modos de entenderlo, de verdades que entran en pugna. En buena medida, la única afirmación posible es que la realidad está ahí, y da de sí hasta un cierto punto, posibilitando y condicionando, pero no es viable un conocimiento absolutamente verdadero, perfecto, ahistórico, intemporal, por tanto no es posible alcanzar la verdad de un modo absoluto e inmutable. De esto ya se dio cuenta K. Popper. La verdad es eso que siempre andamos buscando pero que siempre se nos escapa. Entre otras cosas, porque siempre tiene una dimensión construida. 
¿Qué implicaciones tiene todo esto? La más importante de todas, que no es posible afirmar la existencia de un orden moral inscrito en la naturaleza, que determine de modo unívoco e incuestionable las acciones humanas. Antes bien, la moralidad es una construcción humana que, a tenor de la realidad, busca asignar valores y busca una justificación para unas opciones que, indefectiblemente, serán siempre falibles. De ahí que la ley natural sea una vana ilusión.

\section{La cuestión de la ley natural}

La idea de ley natural aparece en el campo político, para abordar la cuestión de su justificación. El modo de establecer la base del poder era remitirse a los orígenes divinos de quien lo ostentaba. Con ello se consideraban unidas la moral, el derecho positivo y la religión ${ }^{1}$. Esta intuición cobra forma en la antigua Grecia, por obra de autores como Platón, que busca las ideas universales, y sobre todo Aristóteles, quien defiende que existe la naturaleza humana, en la que se establecen ciertas tendencias como modos propios de expresión de la perfección intrínseca al propio ser humano. La realización de un ideal de bien es connatural a cada persona, porque ha de cumplir con el destino que está ya predeterminado y que se inscribe en el mismo ser humano. Sin embargo, es claro que la comprensión de Aristóteles en la Edad Media distorsionó notablemente a este autor. Aristóteles concedió una importancia fundamental a la idea de que la virtud, lejos de ser algo unívoco y establecido para cada humano, era algo que debía ganarse con esfuerzo y tras un proceso de deliberación en el que se sopesaran los extremos viciosos para poder determinar, conforme al individuo específico y a la situación concreta, cuál era el bien propio a realizar.

La idea de la naturaleza como ley cobra una especial importancia en el mundo romano, donde pasa a desempeñar una nueva función: al concebir al ser humano como ciudadano no de una polis, sino de la cosmópolis (ciudadano del mundo), la ley natural será el modo de reconocer a los humanos y garantizar los derechos que les son inherentes. En el mundo griego (la polis) y en el romano (la civitas) se establece que los ciudadanos, por el mero hecho de serlo, tienen ciertos derechos, pero el reconocimiento de derechos a las personas, al margen de su condición de ciudadanía, se sustenta sobre la ley natural, anterior y superior a cualquier ley civil. Es la contraposición entre la ley natural y la

1 Cfr. E. Chiavacci: "Ley natural”, en F. Compagnoni, G. Piana, S. Privitera, M. Vidal (dirs.), Nuevo Diccionario de Teología Moral. Ed. Paulinas, Madrid 1992, 1013-1028.

VERITAS, $N^{\circ} 23$ (Septiembre 2010) 
ley positiva. Las leyes del poder político encuentran un límite en la ley natural, que es inapelable.

Los autores medievales cristianos se apoyan en la ley natural, e insisten en vincularla con la revelación. La naturaleza, en cuanto creada por Dios, consta de una serie de leyes que son expresión de la voluntad divina. Por ello no es cuestionable ese orden natural, que en tanto creado por Dios es superior y anterior al humano mismo. De ahí que no pueda enmendarse o criticarse, sino sólo acatarlo obedientemente. La ley natural, según Agustín de Hipona, tiende a mantener el orden de lo creado $^{2}$. La tarea del ser humano es empeñarse en conocer esa ley y en respetarla y hacerla cumplir. En el ámbito político, la ley natural deja de ser un límite para la legislación positiva, antes bien, se convierte en su base o fundamento: no es ya una garantía para el ciudadano, sino un motivo de obligación. De ahí que la desobediencia a la ley positiva se considerase una ruptura de la ley natural, y por tanto una ofensa hacia Dios.

Tomás de Aquino mantiene una postura diferente ${ }^{3}$. Menos preocupado por el establecimiento de normas objetivas que regulen el comportamiento moral de los individuos, atiende a la intención de quien lleva a cabo la acción, por tanto apela a la conciencia moral, y no tanto a los hechos que se realizan, como en el caso anterior. La acción moral, según la tradición, estaba compuesta de tres elementos: el objeto, las circunstancias y el fin de la acción. Tomás de Aquino está de acuerdo con las autoridades de la época en que el elemento principal es el objeto de la acción moral, sin embargo se pregunta si el objeto es externo o interno, si lo más importante es la elección de la voluntad o la realización concreta. Su conclusión es que la ordenación de la voluntad al fin último bueno, es lo que ha de ser considerado objeto de análisis y, por tanto, si la intención no es contra Dios, no se puede decir que haya pecado.

Esto hace que la ley natural se conciba de modo diferente: el bien moral se refiere a la orientación hacia Dios, no a la ruptura de la ley objetiva. Es un mandato más universal que inspira la acción humana. De aquí se pueden derivar algunos preceptos generales, de fácil deducción y que nadie ignora, que se consideran inmutables. Sin embargo, estos mandatos son tan generales que van poco más allá de la afirmación del ser humano como un ser racional, que ha de continuar la vida y que ha de relacionarse con otros humanos. La concreción de estos mandatos en obligaciones específicas es fruto de una elaboración racional y, por tanto, es falible y cambiante. El mismo Tomás de Aquino afirma que cuanto

2 Contra Faustum, XXII, 27.

3 Summa Theologiae (en adelante, S.Th.), I-II. 
más remota es la deducción a partir de los principios generales, tanto más fácil es encontrar diversidad de opciones y tanto más fácil es el error ${ }^{4}$.

Este modo de concebir la ley natural se refiere, pues, a la capacidad de encontrar unos preceptos orientativos, de los cuales podrán derivarse, por un proceso racional, los mandatos específicos que mejor realicen los valores contenidos en esos preceptos generales. Sin embargo, dista mucho de ser una lista o catálogo de mandatos infalibles e incuestionables que se establecen como ley positiva. Dicho de otro modo, la ley natural no está escrita ni es posible escribirla definitivamente.

Así la ley natural recobra su función política original: la de ser límite para la ley positiva. De ahí que se pueda incluso establecer que es moralmente obligatorio conculcar o desobedecer la ley positiva, si ésta se opone a la realización del bien propugnado por la ley natural. Se distingue así moral de derecho, y se plantea la posibilidad de la existencia de leyes injustas ${ }^{6}$-aunque Tomás de Aquino afirma que a éstas no se las puede considerar propiamente leyes. En esta línea está también F. Suárez-.

Claro que esta idea de Tomás de Aquino no es compartida por todos los autores, pues implica una cierta «subjetivización» de la moral. Ockham y los nominalistas se situarán en una posición bien diferente, considerando que la razón humana no es capaz de encontrar la verdad por mera deducción a partir de los universales. Esto subvierte el orden moral hasta el punto de que se afirma que la ley divina puede muy bien no ser acorde con una presunta racionalidad intrínseca al comportamiento elegido, sino que puede mandar algo absurdo. El ejemplo de los ockhamistas es clarificador: a la pregunta de «si Dios te mandase que lo odiases ¿lo odiarías?»), ellos respondían afirmativamente ${ }^{7}$.

Se produce desde aquí un giro radical en el modo de concebir la ley natural: la razón humana es el modo de manifestación de la voluntad de Dios. Los mandatos de Dios son claros y no inciertos. De ahí que sea posible, evidente y necesaria la elaboración de preceptos y mandatos por deducción racional. La razón no es inventiva, descubridora de los mandatos sobre la base de los valores fundamentales, como quería Tomás de Aquino, sino que es la que promulga los preceptos. Este sistema tiene sentido en un mundo políticamente marcado por el

\footnotetext{
S.Th. I-II, q.94, aa. 2.4.5.

Cfr. "Ley natural", 1017.

Cfr. S.Th. I-II, q.96, a.4.

Sent. IV, q.14 D.
} 
establecimiento de estados de soberanía absoluta, en los que el ejercicio del poder «justo» se asienta mejor en mandatos presuntamente derivados directamente de una ley superior: la ley natural.

Esta época de «deduccionismo moral», en el que se pretende la derivación de un catálogo objetivo de preceptos morales a partir de la ley natural, se extiende hasta nuestros días en la teología moral. Sin embargo, el planteamiento más «subjetivista» de Tomás de Aquino, reaparece al plantearse, ya en el siglo XVII, la dificultad de la relación entre el individuo y el Estado. Se apelará entonces a la ley natural como fundamento de ciertos derechos básicos (derechos naturales) que son un límite de los derechos positivos. El poder político, entendido en la perspectiva contractual, da lugar a que el derecho positivo tenga como función principal la tutela de los derechos naturales de los individuos.

\section{La ley natural en la ética actual}

¿Qué significado tiene todo esto para la reflexión ética actual? La apelación a la ley natural es tremendamente frecuente, sin embargo, tras lo dicho al comienzo respecto a la imposibilidad de admitir que la naturaleza (sea creada por Dios o no) tenga un orden intrínseco cognoscible y bueno en sí mismo, no parece que sea un argumento de gran solidez. No al menos como ha sido entendido frecuentemente, como sistema deductivo de normas a partir de preceptos universales. Tal cosa supondría incurrir en la defensa de un naturalismo bastante simplista.

Sin embargo, para entender la aportación del concepto de ley natural a la ética actual, podemos atender a la perspectiva de P. Ricoeur ${ }^{8}$, quien analizando el surgimiento de la ley moral a partir de la libertad individual, hace un balance de ley natural, a la que califica de «idea monstruosa» por confundir la ley de la libertad y la ley de la naturaleza. No obstante, considera que esta idea puede desempeñar el papel de un concepto límite, conforme a tres funciones posibles: en primer lugar tendría una función «límite-crítica», que sería la más valiosa de todas, porque supone un modo de controlar la ley positiva, un sistema para contrarrestar la posibilidad de un uso arbitrario del poder, por medio de la apelación a

$8 \quad$ P. Ricoeur: "Place de la notion de loi en éthique", Sapienza, vol. 28, n³ (1975), 313-337; ibíd.: Amor y justicia. Caparrós, Madrid 1993, 88-89.

9 Este modo de designar las funciones está tomado de T. Domingo Moratalla: "De la fenomenología a la ética", en T. Domingo et al. Lecturas de Paul Ricoeur. UPCo, Madrid 1998. 
algo que está por encima de esa ley y que destaca lo que ha de salvaguardarse a toda costa, marcando los límites ante posibles interferencias. Quizá ésta es la ganancia más interesante, pues es uno de los fundamentos posibles de los derechos humanos, y está en la base de todas las llamadas a los «elementos comunes» que comparten los seres humanos por el hecho de serlo.

En segundo lugar, hay una función «recurso», menos válida que la anterior, en la que se establece un principio universal, frente a lo aleatorio de las costumbres y las convenciones sociales. En tal caso, se busca «una naturaleza» que sirva de modelo, lo cual es más discutible y difícil de defender. $\mathrm{Y}$ en tercer lugar, existe una función «refugio», definitivamente inaceptable, que apela al concepto de ley natural desde una perspectiva más biológica. La búsqueda de constantes antropológicas, previas a los elementos culturales e históricos, sería inasumible e incurriría en el error de la falacia naturalista. La pauta físicobiológica como guía moral cae en un reduccionismo al no contar con que la naturaleza humana es siempre «naturaleza cultivada». Es decir, el ser humano es siempre un ser biocultural, que no cabe ser entendido sólo por su definición biológica, sino por el continuo interactuante de su dimensión físico-biológica y su dimensión cultural-histórica. En el ámbito de la moral, caer en este tipo de planteamientos ha supuesto la defensa de posturas como la sociobiología más radical, o dejarse embaucar por la publicidad de una revolución genética que promete engañosamente obtener todas las respuestas sobre el ser humano.

La posición de Tomás de Aquino sí resulta más interesante y acorde con los planteamientos post-críticos, y conviene por tanto ahondar un poco más en ella. Tomás de Aquino está más preocupado por defender que toda acción tiende a un fin bueno, más que a deducir preceptos de un principio universal. El fin último es la «razón del bien» (ratio bonitatis), un fundamento de bondad que no tiene contenidos específicos, pues sólo manda hacer el bien y evitar el mal. De ahí que los actos humanos se juzguen en función de ese fin, pero, al mismo tiempo, que sea intrínseco a los mismos un proceso de conocimiento y voluntad, que no es mero cumplimiento de la norma. El ser humano tiene la capacidad única de tomar conciencia del bien y dirigirse libremente hacia él. La libertad no consiste en elegir o no el bien, pues toda elección será una elección del bien, sino en dirigirse al fin último propio del hombre o no.

(...) todo agente obra por un fin, y el fin tiene razón de bien. De ahí que el primer principio de la razón práctica es el que se funda sobre la noción de bien, y se formula así: “el bien es lo que todos apetecen”. En consecuencia, el primer precepto de la ley es éste: "El bien ha de hacerse y buscarse; el 
mal ha de evitarse". Y sobre éste se fundan todos los demás preceptos de la ley natural, de suerte que cuanto se ha de hacer o evitar caerá bajo los preceptos de esta ley en la medida en que la razón práctica lo capte naturalmente como bien humano ${ }^{10}$.

Es interesante comprobar el papel que Tomás de Aquino asigna a la razón humana. Lejos de trabajar con un sistema heterónomo en el que el único papel del entendimiento humano es la deducción de los mandatos, le confiere un rango de mayor importancia, al considerar que siendo el ser humano un ser racional, es una tendencia natural suya la de obrar de acuerdo con la razón, y puesto que la razón — según él—impulsa a obrar con virtud, no es posible que una persona que actúe racionalmente no sea virtuosa.

Sin embargo, al hablar de la naturaleza humana, un concepto fundamental para poder analizar la idea de ley natural, Tomás de Aquino diferencia entre dos significados: aquella que es específica del humano, y aquella que es común al humano y a los demás animales. Aunque Tomás de Aquino trabajará básicamente con la primera, posiblemente la tradición posterior no es tan cuidadosa en la distinción, lo cual lleva a consecuencias de gran calado. Téngase en cuenta que si hablamos de la naturaleza humana como lo que caracteriza y define al ser humano, estamos en una perspectiva más esencialista, en la que se apela a la importancia de un «modo de ser propiamente humano» que es el que se expresaría en forma de ley. Sin embargo, el segundo de los sentidos presupone la existencia de una naturaleza en cuanto tal, más fisicalista, más biológica, que posee un cierto orden y del cual emanan ciertos mandatos de comportamiento. Este segundo modelo es mucho más criticable, por cuanto supone una defensa de un naturalismo ingenuo. El enfoque más «subjetivista» de Tomás de Aquino tiene que ver, claro está, con el primer sentido -que es el que de hecho subyace a su planteamiento-, en el que se intenta especificar lo propio del ser humano, lo que le hace ser lo que es, dejando de lado un condicionamiento físico-biológico, o un presunto orden anterior y superior a él en el que se inscribiría. Este matiz de la perspectiva de Tomás de Aquino es lo que hace más asumible su modelo que el de los tomistas posteriores, desde una visión moderna.

A ello cabe añadir otro dato de suma importancia: Tomás de Aquino considera que la ley natural, precisamente por este modo de entenderla, no puede ser igual para todas las personas. Es propio del ser humano, como se ha dicho, obrar conforme a razón, sin embargo, siguiendo a

$10 \quad$ S.Th., I, q.94. 
Aristóteles, Tomás de Aquino enfatiza que la razón procede de lo común a lo particular, y que es así tanto en el orden especulativo como en el práctico. Ahora bien, es importante diferenciar ambos órdenes. En el orden especulativo, al no tratar de lo contingente, sí es posible hablar de principios universales de los cuales se deducen conclusiones necesarias. Sin embargo, en el orden práctico, puesto que se refiere a los «asuntos humanos», la verdad sólo es la misma para todos a un nivel universal, pero no en el nivel del conocimiento concreto o particular.

(...) en lo tocante a los principios comunes de la razón, tanto especulativa como práctica, la verdad o rectitud es la misma en todos, e igualmente conocida por todos. Mas, si hablamos de las conclusiones particulares de la razón especulativa, la verdad es la misma para todos los hombres, pero no todos la conocen igualmente. (...) Si se trata, en cambio, de las conclusiones particulares de la razón práctica, la verdad o rectitud ni es la misma en todos, ni en aquellos en que es la misma es igualmente conocida.

La ley natural, además, es histórica, puede cambiar. Es la misma para todos los seres humanos en cuanto a sus primeros principios, que son universales, pero no se trata de una verdad inmutable en cuanto a los preceptos de ella derivados, puesto que, por lo dicho, los contenidos concretos son particulares y derivados del ejercicio de la razón. De ahí que puedan ser cambiados ${ }^{11}$.

Este modelo, más dinámico y abierto tiene poco que ver con la exposición cerrada y encastillada de la ley natural que habitualmente se muestra en otros autores posteriores. La afirmación de un «modo natural» propio del ser humano, que lo incita al bien, o mejor, que tiene al bien como fundamento de su acción moral, como un presupuesto formal que después ha de concretarse en opciones específicas por medio de la razón, está mucho más cercana a los modelos actuales postkantianos.

En el fondo, esto no es más que la afirmación de la necesaria imbricación de la reflexión en el devenir histórico del ser humano: porque no es lo mismo hacer ética en el siglo XXI que en el siglo IV a.C. Aristóteles era deudor de la biología que él conocía, a la altura de su tiempo. Kant trataba de construir su teoría desde la física de Newton. La ética no puede construirse al margen del conocimiento del mundo que vamos obteniendo. Probablemente, si Aristóteles viviera en nuestros días afirmaría cosas bien diferentes de las que entonces pudo decir. Por ejemplo, la distinción entre los entes naturales y los entes artificiales, que

$11 \quad$ S.Th., q.94 a.5. 
muestra de un modo tan aparentemente evidente, asignando a los primeros la generación y a los segundos la producción, sería insostenible en la actualidad. Pero su época no permitía pensar otra cosa.

$Y$ es que resulta indefendible a la altura de nuestro tiempo un modelo de ética que pretenda afirmar una presunta ley natural inmutable, apodíctica, absoluta, de la que se deriven, en un proceso estrictamente deductivo, una serie de mandatos, a modo de catálogo de acciones correctas. Ni la realidad es unívoca desde el punto de vista de los valores, ni la razón humana es infalible para conocer la verdad. Por eso, la ética es siempre un proceso deliberativo, en el que se intentan articular los datos del conocimiento de la realidad, con las opciones de valor y sus justificaciones, a la vista de las circunstancias concretas. Es una constatación de la indeterminación y la incertidumbre que acompañan siempre al conocimiento y la acción humanas.

\section{La naturaleza humana como categoría en los debates bioéticos}

Los debates respecto a la validez ética de las intervenciones en el ser humano, que aparentemente se van haciendo posibles con los avances científico-tecnológicos, no sólo se plantea desde un análisis de consecuencias ante las que se reclama prudencia y responsabilidad. En muchos casos se apela a la preservación de la naturaleza humana, indicando que resulta inmoral cualquier intento de modificación que pudiera alterar o amenazar dicha naturaleza.

En este ámbito se puede citar, por ejemplo, a F. Fukuyama que es uno de los grandes detractores de todas aquellas posiciones que argumentan a favor de la intervención tecnológica - genética o de otro tipo- en el ser humano.

Su punto de vista está basado en la afirmación de la existencia de una «esencia» humana que se vería alterada por estas modificaciones y que daría lugar, en su opinión, a un flagrante atentado contra la dignidad. Fukuyama define la naturaleza humana como la suma del comportamiento y las características que son típicas de la especie humana, y que se deben a factores genéticos más que a factores ambientales $^{12}$. Así, se puede decir que, dejando de lado las características contingentes de las personas, hay en cada una de ellas una cierta cualidad humana esencial, que denomina «factor $\mathrm{x}$ » $\mathrm{y}$ que es la base de la

\footnotetext{
12 F. Fukuyama: El fin del hombre. Consecuencias de la revolución biotecnológica. Ediciones B, Barcelona 2002, 214.
} 
dignidad $^{13}$. Es esa naturaleza la que genera una exigencia de igualdad de reconocimiento o de respeto, tal como se ha afirmado de modo predominante en la Modernidad. Y este autor está convencido de que las intervenciones genéticas $-\mathrm{y}$, por extensión, las modificaciones tecnológicas en el ser humano- pondrían en entredicho esa igualdad de derechos o de dignidad. Ese mundo al que estaríamos abocados, en su perspectiva, podría estar más jerarquizado que el actual y podría generar conflictos por haber perdido el concepto de «humanidad común» ${ }^{14}$.

Esta polémica es la que enfrenta a los «bioconservadores», de los que Fukuyama es un notable representante, con los «transhumanistas». El transhumanismo es la posición que defiende la mejora del ser humano para alcanzar un estado superior o posthumano. Promueve una aproximación interdisciplinar para comprender y evaluar las oportunidades de mejorar la condición humana y el organismo humano abiertas por el avance de la tecnología, lo que implica prestar atención a tecnologías como la ingeniería genética, la tecnología de la información, la nanotecnología molecular y la ciencia cognitiva ${ }^{15}$.

En el enfrentamiento entre estas dos posturas se observan argumentos subyacentes, que reflejan una aproximación muy diferente a la cuestión de la responsabilidad que la sociedad actual tiene respecto de la misma configuración del ser humano.

En la línea bioconservadora, y también desde una preocupación por la posible amenaza a la dignidad humana, Leon Kass afirma, por ejemplo, que la modificación tecnológica acabaría por deshumanizarnos, a fuerza de minar «sentidos» tradicionales, como el sentido del ciclo vital, o el sentido del sexo, o el sentido del trabajo. Kass es defensor de «la sabiduría de la repugnancia», inspirada en la heurística del miedo de Hans Jonas $^{16}$, pero quizá más impactante: en ciertos casos especialmente relevantes, la repugnancia sería, según este autor, la expresión emocional de una sabiduría profunda, que está más allá del poder de la razón para poder ser completamente expresada. Se trata de una especie de intuición que, de modo inmediato y sin argumentos, detecta algo perverso que amenaza lo que apreciamos ${ }^{17}$.

Son varias las perspectivas que se engloban en el grupo de los bioconservadores, sin embargo todas ellas comparten la oposición al uso de la tecnología para mejorar las capacidades humanas o para modificar

13 Ibíd., 243.

14 Ibíd., 345.

15 L. FEITO: "H+Transhumanismo”, en L. Feito (ed.), Nuevas perspectivas cientificas y filosóficas sobre el ser humano. Universidad Comillas, Madrid 2007, 219-237.

16 H. JONAS: El principio de responsabilidad. Herder, Barcelona 1994.

17 L. KASS: "The wisdom of repugnance", The New Republic (1997), 22. 
la naturaleza biológica de los seres humanos. Todos ellos están convencidos de que existe una naturaleza humana que es preciso preservar.

Es muy frecuente, en este tipo de posiciones, utilizar argumentos del tipo «jugar a ser Dios», indicando que el ser humano estaría sobrepasando sus límites y queriendo ser creador, lo cual no puede conllevar más que nefastas consecuencias.

En este tipo de planteamientos éticos se insiste en la maldad intrínseca de las acciones tecnológicas orientadas a la mejora. Así se plantea, por ejemplo, la inmoralidad de un exceso de poder humano, que significaría una intromisión en áreas que no le competen, o la ilegitimidad de la modificación por alterar algo natural y por tanto necesariamente bueno, o, lo que es más frecuente, la necesidad de proteger la dignidad de las personas. No se hace, por tanto, un análisis de lo que se derivaría de las acciones, sus consecuencias o sus implicaciones, sino que se establece a priori el valor intrínseco que tienen y, desde ahí, se catalogan las acciones. Así, por ejemplo, la apelación a la dignidad humana es uno de los argumentos más habituales. Rara vez, sin embargo, se analiza en profundidad por qué determinadas acciones se consideran contrarias al respeto debido a la dignidad.

Además, algunas de estas posiciones suponen y asumen planteamientos de corte «naturalista», es decir, afirman la existencia de un orden interno a la naturaleza, que es bueno y no debe ser modificado. Según esta perspectiva, es preferible asumir el azar mutacional, es decir, los cambios que impone la naturaleza a través de las mutaciones, antes que aceptar la intervención humana para modificar la naturaleza conforme a criterios racionales, lo que podríamos denominar «diseño racional».

Quienes defienden el azar mutacional afirman que la naturaleza tiene un equilibrio y orden internos que no deben ser alterados por ser anteriores y superiores al ser humano. La mutación se puede asumir como un mecanismo evolutivo propio de ese orden y por ello no genera conflicto moral. El azar es inevitable, podemos conocer y prevenir sus consecuencias, pero no debemos producir premeditadamente mutaciones o cambios. Cualquier intervención humana alteraría injustificadamente la naturaleza y por tanto se trataría de una manipulación ilegítima, que supone una creencia soberbia en el poder humano. El ser humano estaría «jugando a ser un dios».

También se utilizan argumentos como el de la «pendiente resbaladiza» - es decir, considerar que abrir una posibilidad tecnológica nos lanza a una situación irreversible, de consecuencias morales desastrosas, por lo que es justificable frenar o prohibir dichas 
posibilidades, aun no siendo éstas dañinas-, por ejemplo como lo utiliza Jeremy Rifkin ${ }^{18}$, otro bioconservador bien conocido por su oposición a la ingeniería genética.

En ocasiones, todo esto se adereza con antiutopías futuristas del estilo de Un mundo Feliz de A. Huxley, o se apela a los riesgos tecnológicos o a los riesgos sociales, por ejemplo las posibles discriminaciones y las desigualdades sociales a que se podría dar lugar. En esta línea se sitúan George Annas, Lori Andrews y Rosario Isasi, quienes han propuesto una legislación que establezca que la modificación genética heredable en humanos sea un crimen contra la humanidad, como la tortura o el genocidio.

Dicen estos autores que la nueva especie, o «posthumano», probablemente verá a los viejos humanos «normales» como inferiores, incluso salvajes, y los conducirá a la esclavitud o a la matanza. Los normales, por su parte, pueden ver a los posthumanos como una amenaza y, si pueden, provocarán un ataque preventivo asesinando a los posthumanos antes de que ellos mismos sean asesinados o hechos esclavos. Es finalmente este predecible potencial de genocidio lo que hace de los experimentos de alteración de la especie posibles armas de destrucción masiva, y hace del irresponsable ingeniero genético un potencial bioterrorista ${ }^{19}$.

Además de éstos, uno de los argumentos que han generado mayor debate es la posibilidad de «programar personas», es decir, la posibilidad de seleccionar o mejorar a los individuos, sobre todo cuando se afirma que los padres han de tener la libertad de elegir cómo quieren que sean sus hijos, como defienden los transhumanistas.

Los transhumanistas defienden la capacidad de tomar decisiones sobre la propia vida y el propio cuerpo, conforme al concepto de «selfownership». Afirman que cada uno de nosotros es el dueño de su propia vida, lo cual enlaza con la idea de autonomía que ha venido defendiéndose en terrenos como la bioética, o en la reivindicación de derechos de los ciudadanos. Puesto que las tecnologías de mejora deberían estar disponibles para todo el mundo, cada individuo debería poder decidir cuáles de esas tecnologías desea aplicarse a sí mismo (libertad morfológica), y también los padres deberían decidir qué tecnologías reproductivas utilizar para tener hijos (libertad reproductiva).

\footnotetext{
18 J. RifKIN: El siglo de la biotecnología. Crítica-Marcombo, Barcelona 1999.

19 G. ANNAS, L. ANDREWS, R. ISASI: "Protecting the endangered human: toward an international treaty prohibiting cloning and inheritable alterations", American Journal of Law and Medicine 28 (2002), 151-178.
} 
Este es el planteamiento de Julian Savulescu quien partiendo de la constatación de que todos buscamos mejorarnos, esto es, ser más inteligentes, estar más sanos, tener más fuerza, estar más atractivos, etc., en el caso de que dispusiéramos de una técnica biomédica que nos permitiera hacer mejoras, no sólo no sería inmoral utilizarla, sino que sería obligatorio. Savulescu considera que si pudiéramos hacer que nuestros hijos tuvieran más posibilidades, desde el punto de vista biológico, sería legítimo ofrecérselas. No habría razón para aceptar las mejoras ambientales y no las biológicas, éstas también deben ser utilizadas. En buena medida, su argumentación trata de buscar la coherencia: si aceptamos tratar enfermedades, debemos aceptar la mejora, pues hay una difícil y oscura distinción entre enfermedad o discapacidad — que justifica la terapia- y malestar — que abre paso a la mejora-, teniendo en cuenta la pluralidad en la definición de salud.

Más aún, Savulescu formula un «Principio de beneficencia procreativa ${ }^{20}$ según el cual las parejas, o personas individuales, deben seleccionar al niño, de entre los hijos posibles que podrían tener, del que se pueda esperar que va a tener la mejor vida, o al menos una vida mejor que los otros, basándose en la información relevante disponible. La «mejor vida» se define como aquella que pueda disfrutar de mayor bienestar. Y la legitimidad de su persecución radica en el hecho de que los padres siempre buscan ese objetivo, aunque por medios ambientales (por ejemplo, eligiendo el momento de tener a su hijo cuando su situación económica sea favorable). La novedad está en la aceptación de medios biológicos para lograrlo.

Por ello Savulescu considera que la selección de genes, patológicos o no, la selección de sexo, la selección de embriones, o la mejora son una obligación moral. No se puede, sino que se debe seleccionar y buscar la mejora. No hacerlo, disponiendo de los medios, sería inmoral. La responsabilidad aquí se interpreta como una toma de decisiones que valora las opciones tecnológicas disponibles, desde el derecho a elegir de las personas, propio de una democracia liberal. De ahí que, más que medidas restrictivas frente a los posibles abusos o las consecuencias indeseables, sea necesario promover contramedidas adecuadas como la educación, la persuasión, y una reforma social y cultural $^{21}$.

20 J. Savulescu: "Procreative Beneficence: Why We Should Select the Best Children", Bioethics, vol.15, n 15-6 (2002), 413-426.

21 N. Bostrom, R. Roache: "Human Enhancement: Ethical Issues in Human Enhancement", en J. Ryberg, T. S. Petersen \& Clark Wolf (eds.), New Waves in Applied Ethics. Palgrave, Macmillan 2008. 
Frente a este tipo de planteamientos, y quizá con la influencia del fantasma de la eugenesia nazi que actúa con gran fuerza en el contexto alemán, es imprescindible mencionar a J. Habermas ${ }^{22}$, quien denuncia los afanes de la tecnología genética que busca la mejora, considerando que ello supone, entre otras cosas, una ruptura de los ámbitos de lo subjetivo y lo objetivo, de «lo crecido» y «lo hecho», una forma de instrumentalización y una falta de respeto a la dinámica propia de una naturaleza que se autorregula, y que ha de servir de guía a las intervenciones humanas, so pena de incurrir en grandes males. Habermas considera que las intervenciones genéticas en los seres humanos son un acto de dominación de la naturaleza que supone una autoinvestidura de poderes, y que por tanto modifica nuestra autocomprensión ética de la especie y podría afectar a una comprensión universalista de la moral.

En las sociedades liberales, esto significaría que las decisiones eugenésicas quedarían en manos de los padres, elecciones de clientes sometidos a oferta y demanda según las leyes del mercado, como quiere Savulescu. Pero Habermas considera que la libertad eugenésica de los padres no puede colisionar con la libertad ética de los hijos. De otro modo, las intervenciones de mejora supondrían una imposición inaceptable, puesto que la persona afectada estaría sujeta a intenciones de otros que son irreversibles, independientemente de si las acepta o las rechaza, y que «le impiden comprenderse espontáneamente como el autor indiviso de la propia vida» ${ }^{23}$. Sólo situaciones excepcionales, cuando se trata de evitar males extremos, justificarían la eugenesia, en opinión de Habermas.

Obviamente, un transhumanista convencido de que la tecnología nos permite ser dueños de nuestra vida, respondería a Habermas que sería un error que un individuo creyera que no tiene elección sobre su propia vida sólo porque sus genes hayan sido seleccionados por sus padres, ya que tiene la misma que si su constitución genética fuera el resultado del azar. Y podría darse la circunstancia de que tuviera una mayor autonomía y posibilidad de elección si las modificaciones realizadas hubieran ampliado el conjunto de sus capacidades básicas. Tener más salud, más inteligencia o más talento es, según los transhumanistas, algo que abre oportunidades para la vida.

22 J. HABermas: El futuro de la naturaleza bumana. ¿Hacia una engenesia liberal? Paidós, Barcelona 2002.

23 Ibíd., 87. 


\section{La naturaleza humana como tema abierto}

El intento de apelar a una cierta naturaleza subyacente que permanece como una sustancia inmutable a pesar de los cambios accidentales, es una vieja y querida idea de la filosofía, y un argumento tranquilizador frente a los retos que nos plantean las posibilidades de las tecnologías biomédicas actuales. Sin embargo, tras lo que se ha comentado, un naturalismo ingenuo es indefendible a la altura de nuestro tiempo. Quienes apelen a una naturaleza humana deberán hacerlo desde el conocimiento de la ciencia actual, evitando incurrir en presupuestos dogmáticos.

Con todo, dista de ser un debate cerrado o resuelto, como lo atestiguan los estudios actuales de la neurociencia, donde se ha rescatado de nuevo el tema. Así, S. Pinker ${ }^{24}$ hablando de la naturaleza humana, ha reabierto la discusión en torno a la existencia de algunos elementos innatos en los seres humanos, indicando que existen algunos elementos biológicos que condicionan las capacidades y cualidades de las personas. Recientemente, ha apuntado la existencia de un «nicho cognitivo» ${ }^{25}$, es decir, la preexistencia de mecanismos, principalmente genéticos, que han evolucionado en los linajes humanos desde un tiempo ancestral y que explicarían los rasgos presentes. Con esta teoría intenta ofrecer un marco conceptual evolucionista para justificar el origen de la mente humana como un rasgo más de la selección natural.

Por su parte, M. Gazzaniga ${ }^{26}$, no ha tenido reparos en afirmar que es evidente la existencia de una naturaleza humana única que nos determina de modo claro, existiendo por tanto una ética universal subyacente. Desafortunadamente, tanto este autor como otros de los que se han embarcado en estos estudios, hacen comentarios nada rigurosos, pues confunden religión y filosofía, prescinden de las críticas al positivismo y parecen adoptar ingenuamente una perspectiva de la ciencia como salvadora de nuestras incertidumbres y nuestros males —una visión de la historia de la humanidad que proponía A. Comte en el siglo XIX y que ha sido desechada-, defendiendo la posibilidad de resolver todos los problemas de la filosofía por medio de la descripción biofísica.

Todo esto no hace sino mostrar la vigencia e interés del tema, y su enorme amplitud, ciertamente mucho mayor de lo que aquí se ha

24 S. PINKER: La tabla rasa. La negación moderna de la naturaleza humana. Paidós. Barcelona 2003.

25 S. PINKER: "The cognitive niche: Coevolution of intelligence, sociality, and language", PNAS 107 (Supplement 2) (2010), 8993-8999.

26 M. Gazzaniga: El cerebro ético. Paidós, Barcelona 2006. 
esbozado. Los datos de la genética, la neurociencia u otras disciplinas científicas, van aportando elementos esenciales para la reflexión filosófica, pues no es posible sostener teorías al margen de la ciencia actual, sin embargo, no agotan ni sustituyen el estudio de la complejidad del ser humano desde categorías que, en definitiva, se han venido poniendo a prueba a lo largo de la historia de la cultura y el pensamiento.

Sumario: 1 . El orden de la naturaleza y el ser humano; 2 . La cuestión de la ley natural; 3. La ley natural en la ética actual; 4. La naturaleza humana como categoría en los debates bioéticos; 5 . La naturaleza humana como tema abierto. 